\title{
Sentinel lymph node mapping in gynecological oncology (Review)
}

\author{
JIANG DU $^{1^{*}},{\text { YALING } \mathrm{LI}^{2 *} \text {, QING WANG }}^{1}$, NASRA BATCHU ${ }^{1}$, JUNKAI ZOU $^{1}$, \\ CHAO SUN ${ }^{1}$, SHULAN LV ${ }^{1}$, QING SONG ${ }^{1,3,4}$ and QILING LI ${ }^{1,4}$ \\ ${ }^{1}$ Department of Obstetrics and Gynecology, First Affiliated Hospital, Xi'an Jiaotong University, Xi'an, Shaanxi 710061; \\ ${ }^{2}$ Gongzhuling Health Workers High School, Gongzhuling, Jilin 136100, P.R. China; ${ }^{3}$ Cardiovascular Research Institute, \\ Morehouse School of Medicine, Atlanta, GA 30310, USA; ${ }^{4}$ Big Data Center, First Affiliated Hospital, \\ Xi'an Jiatong University, Xi'an, Shaanxi 710061, P.R. China
}

Received December 14, 2015; Accepted May 18, 2017

DOI: $10.3892 / \mathrm{ol} .2017 .7219$

\begin{abstract}
The intraoperative mapping of sentinel lymph nodes (SLNs) is part of the treatment strategy for a number of types of tumor. To retrospectively compare results from the mapping of pelvic SLNs for gynecological oncology, using distinct dyes, the present review was conducted to determine the clinical significance of SLN mapping for gynecological oncology. In addition, the present study aimed at identifying an improved choice for SLN mapping tracers in clinical application. Each dye exhibits demerits when applied in the clinical environment. The combination of radioisotopes and blue dyes was identified to exhibit the most accurate detection rate of SLN drainage of gynecological oncology. However, contrast agents were unable to identify whether a SLN is positive or negative for metastasis prior to pathologic examination; additional studies are required.
\end{abstract}

\section{Contents}

1. Introduction

2. Literature search

3. Lymphatic tracers

4. Radioisotopes and SLN mapping

5. Blue dye and SLN mapping

6. ICG and SLN mapping

7. Combination of dyes

Correspondence to: Dr Qiling Li, Department of Obstetrics and Gynecology, First Affiliated Hospital, Xi'an Jiaotong University, 277 Yanta West Road, Xi'an, Shaanxi 710061, P.R. China

E-mail: liqiling@mail.xjtu.edu.cn

${ }^{*}$ Contributed equally

Abbreviations: SLN, sentinel lymph node; ICG, indocyanine green; ISB, isosulfan blue

Key words: sentinel lymph node mapping, gynecological oncology, dyes
8. Novel dyes for SLN mapping

9. Conclusions

\section{Introduction}

The presence of lymphatic metastases of solid tumors is an important factor that affects the prognosis in all types of cancer (1-5). In gynecology, surgical treatment is typically combined with radical excision of the local tumor, with full lymphadenectomy in the drainage areas of the tumor. However, pelvic lymph node metastases were identified in between 21 and $26 \%$, only, of patients with stages Ib and stage II (6-8), and $\leq 27 \%$ in early-stage cervical cancer (7-14). In early-stage endometrial cancer, the frequency of lymph node metastasis varies between 0 and $34 \%$ (15). Patients with pelvic lymphadenectomy may experience a number of complications (16), including lymphedema, nerve injury (17) and infection $(18,19)$, particularly patients who are obese, elderly and with cardiovascular diseases $(20,21)$. As an alternative, the sentinel lymph node (SLN) procedure was introduced in 1977 by Cabanas (22) to determine metastasis to the first lymph node by the original tumor (23). When lymphatic metastases occur, the SLNs will be primarily involved (24) and it is hypothesized that if the SLNs do not exhibit metastases, downstream lymph nodes may not exhibit tumor metastases (25). The concept of lymphatic mapping was introduced by Morton et al (26) at the end of the 20th Century, cutaneous lymphoscintigraphy with colloidal gold was used to identify the lymphatic drainage pattern of melanomas located at ambiguous sites. Since 1977, SLN mapping procedures have been included in the treatment for a number of types of tumor, including vulvar (27-29), breast (30), anal (31), colon (32), skin (33), gastric (34), penile (35), esophageal (36), bladder (37), prostatic neoplasm (38) and non-small cell lung cancer (4). A variety of types of lymphatic drainage tracers have been used, including radioisotopes (39), blue dyes (40), indocyanine green (ICG) $(41,42)$ and a limited number of novel agents. The present review aimed at introducing a brief concept of a number of types of lymphatic tracers and to provide guidelines of SLNs mapping for gynecological cancers.

\section{Literature search}

A literature search in PubMed of articles published between January 1, 2000 and May 20, 2015 was conducted to identify 
studies of SLN mapping using key words including 'dyes and sentinel nodes mapping in gynecological cancer', 'dyes and SLN drainage in gynecological oncology', 'blue dyes and sentinel node mapping in gynecological cancer', 'ICG and sentinel node mapping' and 'radioisotopes and SLN mapping'. Searches were restricted to human studies and studies published in the English language. In addition, other auxiliary examinations for SLN information, including transvaginal ultrasound of the pelvis, computed tomography, magnetic resonance imaging and positron emission tomography-computed tomography, and case studies of sentinel node mapping were excluded from the search. Citation lists of the selected studies were verified to ensure sensitivity of the search methods.

\section{Lymphatic tracers}

The principal lymphatic tracers for SLNs of gynecological oncology are radioisotopes, blue dyes, ICG and a limited number of novel agents. Studies were reviewed to introduce concepts of the clinical advantages and disadvantages of these tracers.

\section{Radioisotopes and SLN mapping}

Injection of radiolabeled colloids with intraoperative detection of the sentinel nodes, using gamma-ray detection probes, for breast cancer was introduced in 1993 by Krag et al (43). Surgeons localized the SLNs intraoperatively, on the basis of the signal coming from a hand-held gamma probe $(44,45)$. Injection of the radioisotope may be performed 1 day before surgery or on the morning of surgery (46). ${ }^{99 \mathrm{~m}} \mathrm{Tc}$-labeled human serum albumin colloids and filtered ${ }^{99 \mathrm{~m}} \mathrm{Tc}$-sulfur colloids, two synthetic colloids, exhibit either low residence time in the SLNs or a low clearance rate from the injection site (47-50). Although other radiolabeled colloids may be used (including ${ }^{123} \mathrm{I}$ and ${ }^{201} \mathrm{Tl}$ ), the short half-life of ${ }^{99 \mathrm{~m}} \mathrm{Tc}$ enables shorter radioactive exposure for patients while allowing $>24 \mathrm{~h}$ to determine positive nodes. In addition, smaller particles enable ${ }^{99 \mathrm{~m}} \mathrm{Tc}$ to flow into secondary lymph nodes more rapidly, therefore enabling the determination of an increased number of positive nodes (51-53). Tissue depth, density and coloration may not affect ${ }^{99 \mathrm{~m}} \mathrm{Tc}$-based lymphotropic agents due to the highly penetrating gamma radiation.

In gynecology, the SLNs may be identified prior to surgery by lymphoscintigraphy, using an injection of radioisotopes. Pre- and intra-surgical lymphatic mapping, using ${ }^{99 \mathrm{~m} T c-l a b e l e d ~ p h y t a t e ~ w a s ~ e f f e c t i v e ~ i n ~ i d e n t i f y i n g ~ S L N s ~ i n ~}$ patients undergoing radical hysterectomy and enabled patients to avoid a lymphadenectomy $(54,55)$. Larger particles typically remain longer in lymph nodes; phytate may be more effective in SLN detection, compared with other agents in use. Ogawa et al (56) revealed that the sensitivity of ${ }^{99 \mathrm{~m}} \mathrm{Tc}$-labeled phytate was $100 \%$ and the false negative rate was $0 \%$. In addition, Dzvincuk et al (57) identified that the rate of SLN detection was $79 \%$. ${ }^{99 \mathrm{~m}} \mathrm{Tc}$-sulfur colloid has been identified to improve, compared with isosulfan blue dye, the detection of SLNs in inguinal dissections of patients with vulvar cancer (58), and Bogliolo et al (59) revealed a detection rate of $100 \%$ in patients with vulvar cancer. ${ }^{99 \mathrm{~m}} \mathrm{Tc}$-tilmanocept, which has been approved by the US Food and Drug Administration, demonstrated advantages in head and neck squamous cell carcinoma; however, the efficiency for gynecological oncology remains unknown (60).

The current gamma cameras are not able to provide adequate anatomical information, resulting in the radioactive signal depicted against a two-dimensional black background (61). Radiolabeled isotopes require enough time prior to surgery to enable transit time to SLNs, which may be 1 day before imaging. Additionally, the time between lymphoscintigraphy and surgery remains distinct and has been identified to be 1 day $(51,62)$, between 3 and $6 \mathrm{~h}(63)$, or an interval $<1 \mathrm{~h}(64)$. Although it has been demonstrated that small particles may be taken up by second- or third-tier lymph nodes, an increased volume of injected radiocolloid may be required to decrease distribution (65). Furthermore, the radio signals may be received by an audible gamma-probe when the signals are increased $\geq 10$-fold, compared with background levels (66). Surgeons and patients may receive radio injury prior to and during the surgery; therefore, the organization of pre-surgical radiocolloid application and subsequent lymphoscintigraphy may be difficult and costly (67). If the SLNs are proximal to the original tumor, the 'hotspot' may be lost in the primary injection site, which may be problematic in cancer.

\section{Blue dye and SLN mapping}

The introduction of blue dye mapping was initially introduced by Morton et al (26) in 1992 and it was initially demonstrated in breast cancer in 1994 by Guiliano et al (68). Compared with the increased waiting time for radio isotope dyes to migrate to the lymph nodes, the injection of blue dyes may be administered to patients under anesthesia in surgery (46). Without a gamma-probe, blue dyes are readily taken up by the lymphatics and enable the surgeon to achieve intrasurgical lymphatic mapping of the regional basin. No preparation is required and blue dyes may be stored at room temperature.

Akrivos et al (69) revealed that the overall detection rate exhibited by blue dye was increased, compared with that exhibited by ${ }^{99 \mathrm{~m}} \mathrm{Tc}$ in previous studies $(58,70)$. The SLN positivity rate was identified to be $23 \%$ in endometrial cancer by Kuru et al (71). The overall sentinel node identification rate was $44 \%$ in a previous study of endometrial cancer (72). Schwendinger et al revealed that the detection rate for SLNs was $83 \%$ (73). The SLN detection rate was identified to be markedly increased in laparoscopy compared with that in laparotomy, following patent blue violet pericervical injection, in females with early-stage endometrial cancer (73). The SLN detection procedure using the blue dye technique is a feasible procedure in cervical cancer, as patent blue dye is a cheap, safe and effective tracer which may be used to determine sentinel nodes in carcinoma of the cervix (74). The sensitivity and negative predictive values were 90 and $97 \%$, respectively, in early-stage cervical cancer (73). The detection rate of patent blue in cervical cancer has been identified to be $71 \%$ (67) and O'Boyle et al (75) revealed that the SLNs were identified in $60 \%$ of patients with cervical cancer. 
Blue dyes are easily prepared and exhibit a limited number of risks to patients and surgeons; however, the efficiency of blue dyes in the identification of SLNs is limited. The low molecular mass of blue dyes enables rapid migration in the lymphatics and the retention of the dye in SLNs is poor. As a result, there is limited time for the surgeon to locate and remove the SLNs prior to the dye spreading to other nodes. Typically, dyes are useful only for visualizing superficial lymph nodes (for instance, in breast cancer and melanoma) blue dyes have difficulty reaching SLNs that reside in deep locations, particularly in overweight patients (76). Although uncommon, patients may exhibit an allergic reaction to patent blue dyes $(77,78)$, as cases of anaphylactic shock have previously occurred during the sentinel node procedure in patients with melanoma and breast cancer (79-82).

\section{ICG and SLN mapping}

ICG was initially used as a visible dye marker in the detection of SLNs and it had success comparable with that of conventional dyes. ICG is easy to use, cost-effective, safe and has been used as a tracer for $>40$ years in clinical use $(83,84)$. Fluorescence-guided imaging with ICG has a number of advantages, compared with conventional methods, including real-time lymphography, a low incidence of adverse reactions and an increased sensitivity, without requiring radiation.

The detection rate of fluorescence imaging with ICG has been identified to be increased, compared with that of colorimetric imaging with isosulfan blue (ISB), in females with endometrial cancer undergoing SLN mapping (76). ICG exhibited a markedly increased SLN detection rate, compared with that of blue dyes, in overall and bilateral detection (85). ICG alone exhibited an increased detection rate compared with that exhibited by a combination of blue dye and ICG (95 vs. 93\%, respectively) for uterine and cervical malignancies (86). In addition, the SLN detection rate was 82 and $33 \%$ for cervical and hysteroscopic endometrial injection of ICG, respectively, in endometrial cancer (87).

The low molecular mass of ICG enables rapid migration in the lymphatics to the SLNs (between 1 and $10 \mathrm{~min}$ ); however, the feasibility and accuracy of SLN mapping using ICG adsorbed to human serum albumin has been demonstrated, considering safety, cost and pharmacy preferences in vulvar cancer (88). These approaches have not demonstrated statistically significant improvements in the detection rate; however, the approaches have been identified to improve the strength of the fluorescent signal $(41,89,90)$. Furthermore, leakage and adaptation of ICG fluorescence, causing halation of the image or an autofluorescent glow in the surgical field, has been identified. When the primary SLN was removed, ICG spreading throughout the surgical field makes the identification of other fluorescent nodes difficult. This problem was circumvented by ligating the primary lymphatic duct at a site proximal to the initial SLN to avoid lymphatic fluid retention; ligation of the afferent lymphatic vessel prevents ICG from accumulating in the surgical field $(83,84)$.

\section{Combination of dyes}

The combined techniques appear to exhibit the most sensitivity and highest SLN detection rates (24), with the combination of ${ }^{99 \mathrm{~m}} \mathrm{Tc}$ and blue dyes identified as the most successful, in comparison with other methods $(1,21,24,51,67,91-113)$. Premixing ICG with Tc-nanocolloid provides real-time intrasurgical imaging of the SLNs and appears to be the optimal tracer combination, in terms of the intrasurgical detection rate of the SLNs $(106,114)$. Radioisotope injection into the uterine cervix is useful and safe when combined with blue dye injection into the uterine body for early-stage endometrial cancer (112). However, Frumovitz et al (105) demonstrated that the combination of blue dye and the radiocolloid may not be a useful method in patients with endometrial cancer exhibiting increased risk factors.

\section{Novel dyes for SLN mapping}

Novel dyes including cadmium tellurium quantum dots (115), hybrid tracers (116), near-infrared-emitting polymer nanogels (117), fluorescent-labeled ${ }^{99 m}$ Tc-tilmanocept (118), poly (ethylene glycol)-conjugated bright near-infrared dye (119) and ${ }^{99 \mathrm{~m}} \mathrm{Tc}$ - and ${ }^{68} \mathrm{Ga}-\mathrm{multimodal}$ dextran-based probes (120) have been used for SLN drainage mapping, which exhibited novel advantages; although additional studies are required to be of use in the clinical environment.

A number of injection sites have been described in a previous study, including the cervix, myometrial (sub-serosal), peritumoral by hysteroscopy or by transvaginal ultrasonography, cervical and corporeal injections, which all exhibited improved overall detection rates (121). SLN biopsy, obtained through hysteroscopic injection of ${ }^{99} \mathrm{Tc}$, was identified to be a feasible and safe method (122). Cervical injection, using either blue dye or a radiotracer, results in an increased detection rate and sensitivity (98). Furthermore, a meta-analysis by Kang et al (97) revealed that a cervical injection was the only anatomical site that markedly improved SLN detection. One criticism of cervical injection for endometrial cancer SLN detection is the difference in lymphatic drainage between the cervix and uterine fundus. However, in previous anatomical studies, deep injection into the cervix has demonstrated improved penetration to uterine vessels, parametria, lower uterine segment and cornual regions $(46,107)$. An additional study indicates that cervical injection of dye is a reliable method of identifying the lymphatic drainage of the uterus. However, the technique and timing of application is important for the increased detection rate, particularly when using blue dye and ${ }^{99 \mathrm{~m}} \mathrm{Tc}$ radiocolloid, as the size of the contrast agent affects the uptake into the lymphatic system, speed of transport through the system and retention inside drainage lymph nodes (123).

\section{Conclusions}

There are several types of lymphatic drainage tracers that may be used in the SLN mapping of gynecological oncology. All tracers mentioned exhibit a number of disadvantages in the mapping of lymph nodes and the tracers may only provide the location information of SLNs, without specifying the metastasis arising from the original tumor. Identifying the lymph node metastatic conditions is required in order for surgeons to determine whether the pelvic lymphadenectomy 
may be performed. Additional studies are required to identify contrast agents which may reveal whether a SLN was positive or negative for metastasis, without removing it.

\section{Acknowledgements}

The present review was supported by the International Cooperation Project of Shaanxi Province (grant no. 2013kw-30-04), the National Natural Science Foundation of China (grant no. 81472823) and the Fundamental Research Funds for Xi'an Jiaotong University (grant no. xjj2015093).

\section{References}

1. Tinga DJ, Bouma $\mathbf{J}$ and Aalders JG: Patients with squamous cell versus adeno(squamous) carcinoma of the cervix, what factors determine the prognosis? Int J Gynecol Cancer 2: 83-91, 1992.

2. McMahon CJ, Rofsky NM and Pedrosa I: Lymphatic metastases from pelvic tumors: Anatomic classification, characterization, and staging. Radiology 254: 31-46, 2010.

3. Zivanovic O, Khoury-Collado F, Abu-Rustum NR and Gemignani ML: Sentinel lymph node biopsy in the management of vulvar carcinoma, cervical cancer, and endometrial cancer. Oncologist 14: 695-705, 2009.

4. Shersher DD and Liptay MJ: Status of sentinel lymph node mapping in non-small cell lung cancer. Cancer J 21: 17-20, 2015.

5. Maccauro M, Lucignani G, Aliberti G, Villano C, Castellani MR, Solima E and Bombardieri E: Sentinel lymph node detection following the hysteroscopic peritumoural injection of 99mTc-labelled albumin nanocolloid in endometrial cancer. Eur J Nucl Med Mol Imaging 32: 569-574, 2005.

6. Benedetti-Panici P, Maneschi F, Scambia G, Greggi S, Cutillo G, D'Andrea G, Rabitti C, Coronetta F, Capelli A and Mancuso S: Lymphatic spread of cervical cancer: An anatomical and pathological study based on 225 radical hysterectomies with systematic pelvic and aortic lymphadenectomy. Gynecol Oncol 62: 19-24, 1996.

7. Michel G, Morice P, Castaigne D, Leblanc M, Rey A and Duvillard P: Lymphatic spread in stage Ib and II cervical carcinoma: Anatomy and surgical implications. Obstet Gynecol 91: 360-363, 1998

8. Sakuragi N, Satoh C, Takeda N, Hareyama H, Takeda M, Yamamoto R, Fujimoto T, Oikawa M, Fujino T and Fujimoto S: Incidence and distribution pattern of pelvic and paraaortic lymph node metastasis in patients with stages IB, IIA, and IIB cervical carcinoma treated with radical hysterectomy. Cancer 85 : $1547-1554,1999$.

9. Barranger E, Cortez A, Uzan S, Callard P and Darai E: Value of intraoperative imprint cytology of sentinel nodes in patients with cervical cancer. Gynecol Oncol 94: 175-180, 2004.

10. Benedet JL, Odicino F, Maisonneuve P, Beller U, Creasman WT, Heintz AP, Ngan HY, Sideri M and Pecorelli S: Carcinoma of the cervix uteri. J Epidemiol Biostat 6: 7-43, 2001.

11. Delgado G, Bundy BN, Fowler WC Jr, Stehman FB, Sevin B, Creasman WT, Major F, DiSaia P and Zaino R: A prospective surgical pathological study of stage I squamous carcinoma of the cervix: A gynecologic oncology group study. Gynecol Oncol 35: 314-320, 1989.

12. Landoni F, Maneo A, Colombo A, Placa F, Milani R, Perego P, Favini G, Ferri L and Mangioni C: Randomised study of radical surgery versus radiotherapy for stage Ib-IIa cervical cancer. Lancet 350: 535-540, 1997.

13. Lin YS, Tzeng CC, Huang KF, Kang CY, Chia CC and Hsieh JF: Sentinel node detection with radiocolloid lymphatic mapping in early invasive cervical cancer. Int J Gynecol Cancer 15: 273-277, 2005.

14. Magrina JF, Goodrich MA, Lidner TK, Weaver AL, Cornella JL and Podratz KC: Modified radical hysterectomy in the treatment of early squamous cervical cancer. Gynecol Oncol 72: 183-186, 1999.

15. Creasman WT, Morrow CP, Bundy BN, Homesley HD, Graham JE and Heller PB: Surgical pathologic spread patterns of endometrial cancer. A Gynecologic Oncology Group Study. Cancer 60: 2035-2041, 1987.
16. Sakuragi N: Up-to-date management of lymph node metastasis and the role of tailored lymphadenectomy in cervical cancer. Int J Clin Oncol 12: 165-175, 2007.

17. Kassam AB, Prevedello DM, Carrau RL, Snyderman CH, Thomas A, Gardner P, Zanation A, Duz B, Stefko ST, Byers K and Horowitz MB: Endoscopic endonasal skull base surgery: Analysis of complications in the authors' initial 800 patients. J Neurosurg 114: 1544-1568, 2011.

18. Fuller J, Guderian D, Köhler C, Schneider A and Wendt TG: Lymph edema of the lower extremities after lymphadenectomy and radiotherapy for cervical cancer. Strahlenther Onkol 184: 206-211, 2008.

19. Ayhan A, Celik H and Dursun P: Lymphatic mapping and sentinel node biopsy in gynecological cancers: A critical review of the literature. World J Surg Oncol 6: 53, 2008.

20. Rose PG: Endometrial carcinoma. N Engl J Med 335: 640-649, 1996.

21. Kodama J, Seki N, Ojima Y, Nakamura K, Hongo A and Hiramatsu Y: Risk factors for early and late postoperative complications of patients with endometrial cancer. Eur J Obstet Gynecol Reprod Biol 124: 222-226, 2006.

22. Cabanas RM: An approach for the treatment of penile carcinoma. Cancer 39: 456-466, 1977.

23. Tanis PJ, Nieweg OE, Valdés Olmos RA, Th Rutgers EJ and Kroon BB: History of sentinel node and validation of the technique. Breast Cancer Res 3: 109-112, 2001.

24. van de Lande J, Torrenga B, Raijmakers PG, Hoekstra OS, van Baal MW, Brölmann HA and Verheijen RH: Sentinel lymph node detection in early stage uterine cervix carcinoma: A systematic review. Gynecol Oncol 106: 604-613, 2007.

25. Crane LM, Themelis G, Buddingh KT, Harlaar NJ, Pleijhuis RG, Sarantopoulos A, van der Zee AG, Ntziachristos V and van Dam GM: Multispectral real-time fluorescence imaging for intraoperative detection of the sentinel lymph node in gynecologic oncology. J Vis Exp: pii: 2225, 2010.

26. Morton DL, Wen DR, Wong JH, Economou JS, Cagle LA, Storm FK, Foshag LJ and Cochran AJ: Technical details of intraoperative lymphatic mapping for early stage melanoma. Arch Surg 127: 392-399, 1992.

27. Levenback C, Coleman RL, Burke TW, Bodurka-Bevers D, Wolf JK and Gershenson DM: Intraoperative lymphatic mapping and sentinel node identification with blue dye in patients with vulvar cancer. Gynecol Oncol 83: 276-281, 2001.

28. de Hullu JA, Hollema H, Piers DA, Verheijen RH, van Diest PJ, Mourits MJ, Aalders JG and van Der Zee AG: Sentinel lymph node procedure is highly accurate in squamous cell carcinoma of the vulva. J Clin Oncol 18: 2811-2816, 2000.

29. Dhar KK and Woolas RP: Lymphatic mapping and sentinel node biopsy in early vulvar cancer. BJOG 112: 696-702, 2005.

30. Ahmed M, Purushotham AD and Douek M: Novel techniques for sentinel lymph node biopsy in breast cancer: A systematic review. Lancet Oncol 15: e351-362, 2014.

31. Tehranian S, Treglia G, Krag DN, Dabbagh Kakhki VR, Zakavi SR, Sadeghi R and Keshtgar M: Sentinel node mapping in anal canal cancer: Systematic review and meta-analysis. J Gastrointestin Liver Dis 22: 321-328, 2013.

32. Pallarés-Segura JL, Balague-Pons C, Dominguez-Agustin N, Martinez C, Hernandez P, Bollo J, Targarona-Soler EM and Trias-Folch M: The role of sentinel lymph node in colon cancer evolution. Cir Esp 92: 670-675, 2014 (In English, Spanish).

33. Nakamura Y, Fujisawa Y, Nakamura Y, Maruyama H, Furuta J, Kawachi Y and Otsuka F: Improvement of the sentinel lymph node detection rate of cervical sentinel lymph node biopsy using real-time fluorescence navigation with indocyanine green in head and neck skin cancer. J Dermatol 40: 453-457, 2013.

34. Mitsumori N, Nimura H, Takahashi N, Kawamura M, Aoki H, Shida A, Omura N and Yanaga K: Sentinel lymph node navigation surgery for early stage gastric cancer. World J Gastroenterol 20: 5685-5693, 2014

35. Brouwer OR, van den Berg NS, Mathéron HM, van der Poel HG, van Rhijn BW, Bex A, van Tinteren H, Valdés Olmos RA, van Leeuwen FW and Horenblas S: A hybrid radioactive and fluorescent tracer for sentinel node biopsy in penile carcinoma as a potential replacement for blue dye. Eur Urol 65: 600-609, 2014.

36. Filip B, Scarpa M, Cavallin F, Alfieri R, Cagol M and Castoro C: Minimally invasive surgery for esophageal cancer: A review on sentinel node concept. Surg Endosc 28: 1238-1249, 2014. 
37. Schaafsma BE, Verbeek FP, Elzevier HW, Tummers QR van der Vorst JR, Frangioni JV, van de Velde CJ, Pelger RC and Vahrmeijer AL: Optimization of sentinel lymph node mapping in bladder cancer using near-infrared fluorescence imaging. J Surg Oncol 110: 845-850, 2014.

38. Yuen K, Miura T, Sakai I, Kiyosue A and Yamashita M Intraoperative fluorescence imaging for detection of sentine lymph nodes and lymphatic vessels during open prostatectomy using indocyanine green. J Urol 194: 371-377, 2015.

39. Liptay MJ, D'Amico TA, Nwogu C, Demmy TL, Wang XF Gu L, Litle VR, Swanson SJ and Kohman LJ; Thoracic Surgery Subcommittee of the Cancer and Leukemia Group B: Intraoperative sentinel node mapping with technitium-99 in lung cancer: results of CALGB 140203 multicenter phase II trial. J Thorac Oncol 4: 198-202, 2009.

40. Polom W, Markuszewski M, Rho YS and Matuszewski M: Usage of invisible near infrared light (NIR) fluorescence with indocyanine green (ICG) and methylene blue (MB) in urological oncology. Part 1. Cent European J Urol 67: 142-148, 2014.

41. Schaafsma BE, van der Vorst JR, Gaarenstroom KN, Peters AA, Verbeek FP, de Kroon CD, Trimbos JB, van Poelgeest MI Frangioni JV, van de Velde CJ and Vahrmeijer AL: Randomized comparison of near-infrared fluorescence lymphatic tracers for sentinel lymph node mapping of cervical cancer. Gynecol Oncol 127: 126-130, 2012.

42. Liberale G, Vankerckhove S, Galdon MG, Donckier V, Larsimont D and Bourgeois P: Fluorescence imaging after intraoperative intravenous injection of indocyanine green for detection of lymph node metastases in colorectal cancer. Eur J Surg Oncol 41: 1256-1260, 2015

43. Krag DN, Weaver DL, Alex JC and Fairbank JT: Surgical resection and radiolocalization of the sentinel lymph node in breast cancer using a gamma-probe. Surg Oncol 2: 335-339, 1993

44. Sharma R, Wendt JA, Rasmussen JC, Adams KE, Marshall MV and Sevick-Muraca EM: New horizons for imaging lymphatic function. Ann NY Acad Sci 1131: 13-36, 2008.

45. Ravizzini G, Turkbey B, Barrett T, Kobayashi H and Choyke PL: Nanoparticles in sentinel lymph node mapping. Wiley Interdiscip Rev Nanomed Nanobiotechnol 1: 610-623, 2009.

46. Abu-Rustum NR, Khoury-Collado F and Gemignani ML: Techniques of sentinel lymph node identification for early-stage cervical and uterine cancer. Gynecol Oncol 111 (2 Suppl): S44-S50, 2008.

47. Morais M, Subramanian S, Pandey U, Samuel G, Venkatesh M Martins M, Pereira S, Correia JD and Santos I: Mannosylated dextran derivatives labeled with fac- $\left[\mathrm{M}(\mathrm{CO})_{3}\right]+(\mathrm{M}=(99 \mathrm{~m}) \mathrm{Tc}$ $\mathrm{Re})$ for specific targeting of sentinel lymph node. Mol Pharm 8 : 609-620, 2011

48. Pirmettis I, Arano Y, Tsotakos T, Okada K, Yamaguchi A, Uehara T, Morais M, Correia JD, Santos I, Martins M, et al: New (99m) Tc(CO)3) mannosylated dextran bearing s-derivatized cysteine chelator for sentinel lymph node detection. Mol Pharm 9: $1681-1692,2012$

49. Eshima D, Fauconnier T, Eshima L and Thornback JR: Radiopharmaceuticals for lymphoscintigraphy: Including dosimetry and radiation considerations. Semin Nucl Med 30: 25-32, 2000.

50. Wilhelm AJ,Mijnhout GS and Franssen EJ: Radiopharmaceuticals in sentinel lymph-node detection-an overview. Eur J Nucl Med 26 (4 Suppl): S36-S42, 1999.

51. Niikura H, Okamura C, Akahira J, Takano T, Ito K, Okamura K and Yaegashi N: Sentinel lymph node detection in early cervical cancer with combination $99 \mathrm{mTc}$ phytate and patent blue. Gynecol Oncol 94: 528-532, 2004

52. Verheijen RH, Pijpers R, van Diest PJ, Burger CW, Buist MR and Kenemans P: Sentinel node detection in cervical cancer. Obstet Gynecol 96: 135-138, 2000

53. Dargent D, Martin X and Mathevet P: Laparoscopic assessment of the sentinel lymph node in early stage cervical cancer. Gynecol Oncol 79: 411-415, 2000.

54. Silva LB, Silva-Filho AL, Traiman P, Triginelli SA, de Lima CF, Siqueira CF, Barroso A, Rossi TM, Pedrosa MS, Miranda D and Melo JR: Sentinel node detection in cervical cancer with (99m) Tc-phytate. Gynecol Oncol 97: 588-595, 2005.

55. Du XL, Sheng XG, Jiang T, Li QS, Yu H, Pan CX, Lu CH, Wang $C$ and Song QQ: Sentinel lymph node biopsy as guidance for radical trachelectomy in young patients with early stage cervical cancer. Bmc Cancer 11: 157, 2011.
56. Ogawa S, Kobayashi H, Amada S, Yahata H, Sonoda K, Abe K, Baba S, Sasaki M, Kaku T and Wake N: Sentinel node detection with $(99 \mathrm{~m}) \mathrm{Tc}$ phytate alone is satisfactory for cervical cancer patients undergoing radical hysterectomy and pelvic lymphadenectomy. Int J Clin Oncol 15: 52-58, 2010.

57. Dzvincuk P, Pilka R, Kudela M and Koranda P: Sentinel lymph node detection using $99 \mathrm{mTc}$-nanocolloid in endometrial cancer. Ceska Gynekol 71: 231-236, 2006

58. Moore RG, DePasquale SE, Steinhoff MM, Gajewski W, Steller M, Noto R and Falkenberry S: Sentinel node identification and the ability to detect metastatic tumor to inguinal lymph nodes in squamous cell cancer of the vulva. Gynecol Oncol 89: 475-479, 2003.

59. Bogliolo S, Marchiole P, Sala P, Giardina E, Villa G, Fulcheri E and Menada MV: Sentinel node mapping with radiotracer alone in vulvar cancer: A five year single-centre experience and literature review. Eur J Gynaecol Oncol 36: 10-15, 2015.

60. Surasi DS, O'Malley J and Bhambhvani P: 99mTc-Tilmanocept: A novel molecular agent for lymphatic mapping and sentinel lymph node localization. J Nucl Med Technol 43: 87-91, 2015.

61. Vermeeren L, Valdés Olmos RA, Meinhardt W, Bex A, van der Poel HG, Vogel WV, Sivro F, Hoefnagel CA and Horenblas S: Intraoperative radioguidance with a portable gamma camera: A novel technique for laparoscopic sentinel node localisation in urological malignancies. Eur J Nucl Med Mol Imaging 36: 1029-1036, 2009

62. Buist MR, Pijpers RJ, van Lingen A, van Diest PJ, Dijkstra J, Kenemans P and Verheijen RH: Laparoscopic detection of sentinel lymph nodes followed by lymph node dissection in patients with early stage cervical cancer. Gynecol Oncol 90: 290-296, 2003.

63. van Dam PA,Hauspy J,Vanderheyden T, Sonnemans H,Spaepen A Eggenstein G, Dirix L and Verkinderen L: Intraoperative sentinel node identification with Technetium-99m-labeled nanocolloid in patients with cancer of the uterine cervix: A feasibility study. Int J Gynecol Cancer 13: 182-186, 2003.

64. Plante M, Renaud MC, Têtu B, Harel F and Roy M: Laparoscopic sentinel node mapping in early-stage cervical cancer. Gynecol Oncol 91: 494-503, 2003.

65. Ballester M, Rouzier R, Coutant C, Kerrou K and Daraï E: Limits of lymphoscintigraphy for sentinel node biopsy in women with endometrial cancer. Gynecol Oncol 112: 348-352, 2009.

66. Niikura H, Okamura C, Utsunomiya H, Yoshinaga K, Akahira J, Ito $\mathrm{K}$ and Yaegashi N: Sentinel lymph node detection in patients with endometrial cancer. Gynecol Oncol 92: 669-674, 2004.

67. Rob L, Strnad P, Robova H, Charvat M, Pluta M, Schlegerova D and Hrehorcak M: Study of lymphatic mapping and sentinel node identification in early stage cervical cancer. Gynecol Oncol 98: 281-288, 2005.

68. Giuliano AE, Kirgan DM, Guenther JM and Morton DL: Lymphatic mapping and sentinel lymphadenectomy for breast cancer. Ann Surg 220: 391-398, 1994.

69. Akrivos N, Rodolakis A, Vlachos G, Sotiropoulou M, Papantoniou V, Biliatis I, Haidopoulos D, Thomakos N, Simou M and Antsaklis A: Detection and credibility of sentinel node in vulvar cancer: A single institutional study and short review of literature. Arch Gynecol Obstet 284: 1551-1556, 2011.

70. Radziszewski J, Kowalewska M, Jedrzejczak T, Kozlowicz-Gudzinska I, Nasierowska-Guttmejer A, Bidzinski M and Siedlecki JA: The accuracy of the sentinel lymph node concept in early stage squamous cell vulvar carcinoma. Gynecol Oncol 116: 473-477, 2010.

71. Kuru O, Topuz S, Sen S, Iyibozkurt C and Berkman S: Sentinel lymph node biopsy in endometrial cancer: Description of the technique and preliminary results. J Turk Ger Gynecol Assoc 12: 204-208, 2011.

72. Gien LT, Kwon JS and Carey MS: Sentinel node mapping with isosulfan blue dye in endometrial cancer. J Obstet Gynaecol Can 27: 1107-1112, 2005.

73. Schwendinger V, Müller-Holzner E, Zeimet AG and Marth C: Sentinel node detection with the blue dye technique in early cervical cancer. Eur J Gynaecol Oncol 27: 359-362, 2006

74. Acharya BC and Jihong L: Sentinel lymph node detection in patients with early cervical cancer. JNMA J Nepal Med Assoc 48: 287-291, 2009.

75. O'Boyle JD, Coleman RL, Bernstein SG, Lifshitz S, Muller CY and Miller DS: Intraoperative lymphatic mapping in cervix cancer patients undergoing radical hysterectomy: A pilot study. Gynecol Oncol 79: 238-243, 2000. 
76. Sinno AK, Fader AN, Roche KL, Giuntoli RL II and Tanner EJ: A comparison of colorimetric versus fluorometric sentine lymph node mapping during robotic surgery for endometrial cancer. Gynecol Oncol 134: 281-286, 2014.

77. Bricou A, Barranger E, Uzan S and Darai E: Anaphylactic shock during the sentinel lymph node procedure for cervical cancer. Gynecol Oncol 114: 375-376, 2009.

78. Barthelmes L, Goyal A, Newcombe RG, McNeill F and Mansel RE; NEW START and ALMANAC study groups: Adverse reactions to patent blue V dye-The NEW START and ALMANAC experience. Eur J Surg Oncol 36: 399-403, 2010.

79. Wöhrl S, Focke M, Hinterhuber G, Stingl G and Binder M: Near-fatal anaphylaxis to patent blue V. Br J Dermatol 150 1037-1038, 2004.

80. Forschner K, Kleine-Tebbe A, Zuberbier T and Worm M: Type I sensitization towards patent blue as a cause of anaphylaxis. Allergy 58: 457-458, 2003.

81. Woltsche-Kahr I, Komericki P, Kränke B, Brabek E, Horn M, Schuller-Petrovic S, Richtig E and Aberer W: Anaphylactic shock following peritumoral injection of patent blue in sentinel lymph node biopsy procedure. Eur J Surg Oncol 26: 313-314, 2000.

82. Ortiz D, Alvikas J and Riker AI: A case of severe anaphylactic reaction secondary to isosulfan blue dye injection. Ochsner J 15 $183-186,2015$

83. Noguchi M, Inokuchi M and Zen Y: Complement of peritumoral and subareolar injection in breast cancer sentinel lymph node biopsy. J Surg Oncol 100: 100-105, 2009.

84. Tong M, Guo W and Gao W: Use of fluorescence imaging in combination with patent blue dye versus patent blue dye alone in sentinel lymph node biopsy in breast cancer. J Breast Cancer 17: 250-255, 2014.

85. How J, Gotlieb WH, Press JZ, Abitbol J, Pelmus M, Ferenczy A, Probst S, Gotlieb R, Brin S and Lau S: Comparing indocyanine green, technetium, and blue dye for sentinel lymph node mapping in endometrial cancer. Gynecol Oncol 137: 436-442, 2015

86. Jewell EL, Huang JJ, Abu-Rustum NR, Gardner GJ, Brown CL, Sonoda Y, Barakat RR, Levine DA and Leitao MM Jr: Detection of sentinel lymph nodes in minimally invasive surgery using indocyanine green and near-infrared fluorescence imaging for uterine and cervical malignancies. Gynecol Oncol 133: 274-277, 2014

87. Rossi EC, Jackson A, Ivanova A and Boggess JF: Detection of sentinel nodes for endometrial cancer with robotic assisted fluorescence imaging: Cervical versus hysteroscopic injection. Int J Gynecol Cancer 23: 1704-1711, 2013.

88. Hutteman M, van der Vorst JR, Gaarenstroom KN, Peters AA, Mieog JS, Schaafsma BE, Löwik CW, Frangioni JV, van de Velde CJ and Vahrmeijer AL: Optimization of near-infrared fluorescent sentinel lymph node mapping for vulvar cancer. Am J Obstet Gynecol 206: 89, 2012.

89. Schaafsma BE, Verbeek FP, Peters AA, van der Vorst JR, de Kroon CD, van Poelgeest MI, Trimbos JB, van de Velde CJ, Frangioni JV, Vahrmeijer AL and Gaarenstroom KN: Near-infrared fluorescence sentinel lymph node biopsy in vulvar cancer: A randomised comparison of lymphatic tracers. BJOG 120: 758-764, 2013.

90. van der Vorst JR, Hutteman M, Gaarenstroom KN, Peters AA, Mieog JS, Schaafsma BE, Kuppen PJ, Frangioni JV, van de Velde CJ and Vahrmeijer AL: Optimization of near-infrared fluorescent sentinel lymph node mapping in cervical cancer patients. Int J Gynecol Cancer 21: 1472-1478, 2011.

91. Martinez-Palones JM, Gil-Moreno A, Pérez-Benavente MA, Roca I and Xercavins J: Intraoperative sentinel node identification in early stage cervical cancer using a combination of radiolabeled albumin injection and isosulfan blue dye injection. Gynecol Oncol 92: 845-850, 2004.

92. Lindell G, Jonsson C, Ehrsson RJ, Jacobsson H, Danielsson KG, Källström BN and Larson B: Evaluation of preoperative lymphoscintigraphy and sentinel node procedure in vulvar cancer. Eur J Obstet Gynecol Reprod Biol 152: 91-95, 2010.

93. How J, Lau S, Press J, Ferenczy A, Pelmus M, Stern J, Probst S, Brin S, Drummond N and Gotlieb W: Accuracy of sentine lymph node detection following intra-operative cervical injection for endometrial cancer: A prospective study. Gynecol Oncol 127: 332-337, 2012.

94. Hassanzade M, Attaran M, Treglia G, Yousefi Z and Sadeghi R: Lymphatic mapping and sentinel node biopsy in squamous cell carcinoma of the vulva: Systematic review and meta-analysis of the literature. Gynecol Oncol 130: 237-245, 2013
95. Kadkhodayan S, Shiravani Z, Hasanzadeh M, Sharifi N, Yousefi Z, Fattahi A and Sadeghi R: Lymphatic mapping and sentinel node biopsy in endometrial cancer-a feasibility study using cervical injection of radiotracer and blue dye. Nucl Med Rev Cent East Eur 17: 55-58, 2014.

96. Maffuz A, Quijano F, López D and Hernández-Ramírez D: Laparoscopic radical hysterectomy with lymphatic mapping and sentinel lymph node biopsy in early cervical cancer. Ginecol Obstet Mex 78: 345-351, 2010.

97. Kang S, Yoo HJ, Hwang JH, Lim MC, Seo SS and Park SY: Sentinel lymph node biopsy in endometrial cancer: Meta-analysis of 26 studies. Gynecol Oncol 123: 522-527, 2011.

98. Ansari M, Rad MA, Hassanzadeh M, Gholami H, Yousefi Z, Dabbagh VR and Sadeghi R: Sentinel node biopsy in endometrial cancer: Systematic review and meta-analysis of the literature. Eur J Gynaecol Oncol 34: 387-401, 2013.

99. Levinson KL and Escobar PF: Is sentinel lymph node dissection an appropriate standard of care for low-stage endometrial cancers? A review of the literature. Gynecol Obstet Invest 76: 139-150, 2013

100. Touboul C, Bentivegna E, Uzan C, Gouy S, Pautier P, Lhommé C, Duvillard P, Haie-Meder C and Morice P: Sentinel lymph node in endometrial cancer: A review. Curr Oncol Rep 15: 559-565, 2013.

101. Robova H, Rob L, Halaska MJ, Pluta M and Skapa P: Current status of sentinel lymph node mapping in the management of endometrial cancer. Expert Rev Anticancer Ther 13: 55-61, 2013.

102. Coutant C, Morel O, Delpech Y, Uzan S, Daraï E and Barranger E: Laparoscopic sentinel node biopsy in cervical cancer using a combined detection: 5-years experience. Ann Surg Oncol 14: 2392-2399, 2007.

103. Wydra D, Sawicki S and Emerich J: Sentinel node identification in cervical cancer patients: A feasibility study. Ginekol Pol 78: 191-195, 2007 (In Polish).

104. Roca I, Caresia AP, Gil-Moreno A, Pifarre P, Aguade-Bruix S, Castell-Conesa J, Martínez-Palones JM and Xercavins J: Usefulness of sentinel lymph node detection in early stages of cervical cancer. Eur J Nucl Med Mol Imaging 32: 1210-1216, 2005 .

105. Frumovitz M, Bodurka DC, Broaddus RR, Coleman RL, Sood AK, Gershenson DM, Burke TW and Levenback CF: Lymphatic mapping and sentinel node biopsy in women with high-risk endometrial cancer. Gynecol Oncol 104: 100-103, 2007.

106. Handgraaf HJ, Verbeek FP, Tummers QR, Boogerd LS, van de Velde CJ, Vahrmeijer AL and Gaarenstroom KN: Real-time near-infrared fluorescence guided surgery in gynecologic oncology: A review of the current state of the art. Gynecol Oncol 135: 606-613, 2014

107. Khoury-Collado F and Abu-Rustum NR: Lymphatic mapping in endometrial cancer: A literature review of current techniques and results. Int J Gynecol Cancer 18: 1163-1168, 2008.

108. Sevcík L, Klát J, Gráf P, Koliba P, Curík R and Kraft O: Sentinel node detection in early stage of cervical carcinoma using 99mTc-nanocolloid and blue dye. Ceska Gynekol 72: 120-125, 2007 (In Czech).

109. Delaloye JF, Pampallona S, Chardonnens E, Fiche M, Lehr HA, De Grandi $P$ and Delaloye AB: Intraoperative lymphatic mapping and sentinel node biopsy using hysteroscopy in patients with endometrial cancer. Gynecol Oncol 106: 89-93, 2007.

110. Rob L, Robova H, Pluta M, Strnad P, Kacirek J, Skapa P and Taborska K: Further data on sentinel lymph node mapping in vulvar cancer by blue dye and radiocolloids Tc99. Int J Gynecol Cancer 17: 147-153, 2007.

111. Sevcík L, Klát J, Gráf P, Koliba P, Curík R, Kraft O, Mládĕnka J and Dancíková Z: Lymphatic mapping and detection of sentinel node in early stages of cervical carcinoma. Ceska Gynekol 71: 411-415, 2006

112. Niikura H, Kaiho-Sakuma M, Tokunaga H, Toyoshima M, Utsunomiya $\mathrm{H}$, Nagase $\mathrm{S}$, Takano T, Watanabe M, Ito K and Yaegashi N: Tracer injection sites and combinations for sentinel lymph node detection in patients with endometrial cancer. Gynecol Oncol 131: 299-303, 2013.

113. Roca I, Caresia AP, Gil-Moreno A, Pifarre P, Aguade-Bruix S, Castell-Conesa J, Martínez-Palones JM and Xercavins J: Usefulness of sentinel lymph node detection in early stages of cervical cancer. Eur J Nucl Med Mol Imaging 32: 1210-1216, 2005 . 
114. Verbeek FP, Tummers QR, Rietbergen DD, Peters AA, Schaafsma BE, van de Velde CJ, Frangioni JV, van Leeuwen FW, Gaarenstroom KN and Vahrmeijer AL: Sentinel lymph node biopsy in vulvar cancer using combined radioactive and fluorescence guidance. Int J Gynecol Cancer 25: 1086-1093, 2015.

115. Si C, Zhang Y, Lv X, Yang W, Ran Z and Sun P: In vivo lymph node mapping by Cadmium Tellurium quantum dots in rats. J Surg Res 192: 305-311, 2014.

116. Van den Berg NS, Buckle T, Kleinjan GI, Klop WM, Horenblas S, Van Der Poel HG, Valdés-Olmos RA and Van Leeuwen FI: Hybrid tracers for sentinel node biopsy. Q J Nucl Med Mol Imaging 58: 193-206, 2014.

117. Noh YW, Kong SH, Choi DY, Park HS, Yang HK, Lee HJ, Kim HC, Kang KW, Sung MH and Lim YT: Near-infrared emitting polymer nanogels for efficient sentinel lymph node mapping. ACS Nano 6: 7820-7831, 2012.

118. Emerson DK, Limmer KK, Hall DJ, Han SH, Eckelman WC, Kane CJ, Wallace AM and Vera DR: A receptor-targeted fluorescent radiopharmaceutical for multireporter sentinel lymph node imaging. Radiology 265: 186-193, 2012.

119. Proulx ST, Luciani P, Christiansen A, Karaman S, Blum KS Rinderknecht M, Leroux JC and Detmar M: Use of a PEG-conjugated bright near-infrared dye for functional imaging of rerouting of tumor lymphatic drainage after sentinel lymph node metastasis. Biomaterials 34: 5128-5137, 2013
120. Morais M, Campello MP, Xavier C, Heemskerk J, Correia JD, Lahoutte T, Caveliers V, Hernot S and Santos I: Radiolabeled mannosylated dextran derivatives bearing an NIR-fluorophore for sentinel lymph node imaging. Bioconjug Chem 25: 1963-1970, 2014.

121. Cormier B, Rozenholc AT, Gotlieb W, Plante M and Giede C; Communities of Practice (CoP) Group of the Society of Gynecologic Oncology of Canada (GOC): Sentinel lymph node procedure in endometrial cancer: A systematic review and proposal for standardization of future research. Gynecol Oncol 138: 478-485, 2015.

122. Favero G, Pfiffer T, Ribeiro A, Carvalho JP, Baracat EC, Mechsner S, Chiantera V, Köhler C and Schneider A: Laparoscopic sentinel lymph node detection after hysteroscopic injection of technetium-99 in patients with endometrial cancer. Int J Gynecol Cancer 25: 423-430, 2015.

123. Cousins A, Thompson SK, Wedding AB and Thierry B: Clinical relevance of novel imaging technologies for sentinel lymph node identification and staging. Biotechnol Adv 32: 269-279, 2014. 